\title{
Windbreaks for odour dispersion
}

\author{
S. Barrington ${ }^{1}$, L. Xingjun ${ }^{1}$, D. Choinière ${ }^{2} \&$ S. Prasher ${ }^{1}$ \\ ${ }^{I}$ Faculty of Agricultural and Environmental Sciences, \\ Macdonald Campus of McGill University, Québec, Canada \\ ${ }^{2}$ Consumaj inc., Québec, Canada
}

\begin{abstract}
Windbreaks are believed to help disperse odours emitted by livestock facilities. This project compared odour dispersion for a site without and another with a windbreak consisting of a single row of deciduous trees with an optical porosity of $35 \%$. Both sites, without and with a windbreak were subjected to the emission of swine manure odours produced by an odour generator and the resulting odour plume was measured by three groups of four trained panellists calibrated using a forced choice dynamic olfactometer. This calibration was used to relate the group's field odour intensity perception to an actual odour concentration in odour units (OU). In September 2004, the windbreak site was evaluated 15 times while the site without a windbreak was evaluated 4 times. The odour plume which developed on both sites was found to be quite erratic with zones of high odour concentration intercepted and others of low and even non-detectable odour concentration. Nevertheless, a regression method using classification for the data on each site indicated that the windbreak could reduce the odour dispersion distance by $20 \%$, on the average.
\end{abstract}

Keywords: windbreak, odour dispersion, separation distance.

\section{Introduction}

The development of the livestock industry in North America and in Europe is jeopardized by their emissions of odours which are a nuisance for neighbours. These odours are produced mainly during the handling of manures, but can also originate from feed storage and dust emissions. Since there are no technologies which can completely eliminate these odours, livestock operations and environmental authorities use air dilution as remediation measure. The concept consists in building the livestock operation far enough that ambient climatic and 
atmospheric conditions can dilute the emitted odours below their threshold before reaching neighbouring sites. Such distances separating the livestock shelters from the neighbouring buildings are called "set back" or "separation" distances. Most province in Canada, state in the USA and country in Europe have adopted a method of calculating setback distances based on practices adopted by local livestock operations, climatic conditions and topography [1]. Among other options, this method allows for the introduction of correction factors accounting for the use of odour attenuation technologies.

Natural windbreaks are known to affect air currents and improve air mixing, thus be able to reduce separation or setback distances between livestock operations and their neighbours [2,3]. Accordingly, the objective of this paper was to compare the length and strength of the odour plume developing in the presence and absence of a natural windbreak.

\section{Method}

\subsection{Site and equipment}

The sites without and with a windbreak were located on relatively flat farm land with a slope of $0.1 \%$ and in the absence of other trees or fences, in the region South West of Montreal, Canada. The experimental windbreak consisted of a single row of deciduous trees offering an optical density of $35 \%$. A mobile odour generator was used to emit a controlled level of swine manure odour and to carry out the test away from any infrastructure capable of interfering with the results. During the tests, the odour generator was positioned $15 \mathrm{~m}$ upwind from the windbreak and liquid swine manure was used to produce the odour source. A weather tower was installed $200 \mathrm{~m}$ upwind from the site to measure, every minute, wind velocity and direction and ambient air temperature.

\subsection{Method}

The wind direction was measured before starting each test to establish the monitoring path of the three groups of four trained panellists. Five minutes after starting the odour generator, the panellists started to walk their designated path, stopping at random locations, taking off their face mask and evaluating the odour for 1 minute using a scale of 1 to 10. During this time, odour samples were collected from the outlet of the odour generator every 30 minutes. Once the odour plume was evaluated, up to $500 \mathrm{~m}$ downwind from the odour generator, the panellists travelled to the olfactory laboratory, where they were rated using nbutanol, and were used to evaluate the odour samples collected at the generator. At the same time, their field odour intensity perception was correlated to an actual odour concentration in terms of odour units (OU). A forced choice dynamic olfactometer was used for this laboratory work. The sites without and with a windbreak were evaluated 4 and 15 times, respectively in September 2004, when the ambient air temperature ranged between 18 and $26^{\circ} \mathrm{C}$ (Table 1). 
Table 1: $\quad$ Experimental conditions for windbreak evaluation.

\begin{tabular}{|c|c|c|c|c|c|}
\hline \multirow[t]{2}{*}{ site } & \multirow{2}{*}{$\begin{array}{c}\text { test } \\
\text { number }\end{array}$} & \multirow{2}{*}{$\begin{array}{l}\text { Average } \\
\text { OU } \\
\text { generated }\end{array}$} & \multicolumn{2}{|c|}{ Average wind } & \multirow{2}{*}{$\begin{array}{c}\text { Average } \\
\text { temperature } \\
\left({ }^{\circ} \mathrm{C}\right)\end{array}$} \\
\hline & & & $\begin{array}{l}\text { Velocity } \\
(\mathrm{m} / \mathrm{s})\end{array}$ & direction & \\
\hline \multirow{5}{*}{$\begin{array}{c}\text { without } \\
\text { windbreak }\end{array}$} & 1 & 621 & 6.4 & 90 & 19 \\
\hline & 2 & 760 & 6.0 & 90 & 20 \\
\hline & 3 & 859 & 2.5 & 50 & 17 \\
\hline & 4 & 551 & 2.5 & 50 & 20 \\
\hline & average & 698 & & & \\
\hline \multirow{16}{*}{$\begin{array}{c}\text { with } \\
\text { windbreak }\end{array}$} & 1 & 1373 & 3.9 & 90 & 21 \\
\hline & 2 & 492 & 4.4 & 90 & 23 \\
\hline & 3 & 578 & 4.7 & 40 & 18 \\
\hline & 4 & 585 & 4.2 & 40 & 19 \\
\hline & 5 & 214 & 1.0 & 60 & 22 \\
\hline & 6 & 218 & 1.1 & 70 & 20 \\
\hline & 7 & 5360 & 1.2 & 30 & 22 \\
\hline & 8 & 1096 & 2.7 & 20 & 27 \\
\hline & 9 & 559 & 1.2 & 50 & 23 \\
\hline & 10 & 294 & 1.0 & 40 & 26 \\
\hline & 11 & 744 & 5.1 & 90 & 28 \\
\hline & 12 & 745 & 1.5 & 90 & 23 \\
\hline & 13 & 1879 & 1.5 & 40 & 24 \\
\hline & 14 & 1352 & 1.4 & 50 & 21 \\
\hline & 15 & 846 & 2.2 & 60 & 26 \\
\hline & average & 997 & & & \\
\hline average & & 934 & & & \\
\hline
\end{tabular}

Note: a wind direction of $90^{\circ}$ is perpendicular to the windbreak.

\subsection{Analysis of the data}

The odour observations and evaluations of all four panellists in each group where averaged before analyzing the data. All odour plumes were standardized for comparison. The odour generator produced a different odour level because the swine manure had to be changed before each test and, also, during each test, the odour intensity would decrease over time, but no more than $50 \%$. Thus, the odour concentration measured at every point by each group of panellists, at a given time, was divided by the odour concentration of the generator at that time, and multiplied by the average odour level of 934 OU (odour unit) calculated from all 19 tests. Furthermore, the wind direction with respect to the windbreak was readjusted to $90^{\circ}$ (perpendicular to the windbreak) for purposes of comparison. For each 10 minute of wind direction and speed measurement, the windbreak was assumed to stand perpendicular to the average wind direction and 
new $\mathrm{x}$ and $\mathrm{y}$ coordinates were computed for each odour point observed by defining them as perpendicular and parallel to the windbreak, respectively, with the odour generator standing at the origin.

To compare the odour plumes on both sites, without and with windbreak, a regression analysis was performed with classification, using SAS $[4,5]$ and all the data collected. The least square method was used to establish the significance of the treatment (absence or presence of a windbreak) at a $95 \%$ confidence level.

\section{Results and discussion}

\subsection{The typical odour plume shape}

The respective and typical odour plumes which developed on both sites, without and with a windbreak, are illustrated in Figure 1a and b. Although the odour intensity was found to drop with distance away from the odour generator, the odour plumes were far from being uniform. Rather, zones of peak odour concentration were surrounded by other zones of low and even non-detectable odour concentration.

For the site without windbreak, the first zone of high odour concentration of $10 \mathrm{OU}$ was observed at $75 \mathrm{~m}$ downwind from the generator and its intensity dropped with distance, but still remained over 2 OU even at a distance of $500 \mathrm{~m}$. Also, the drop in odour intensity was progressive with distance away from the source.

For the site with the windbreak, the zones of highest odour concentration occurred immediately on the leeward side of the trees, reached a value of $30 \mathrm{OU}$ which was much higher than that of the no windbreak site, and spanned a distance of $100 \mathrm{~m}$. Nevertheless, for distances greater than $100 \mathrm{~m}$, the odour concentration dropped drastically, to become undetectable at a distance of $500 \mathrm{~m}$. The windbreak therefore appeared to trap the odours on its leeward side, and then to release these odours with a dilution effect.

\subsection{Comparison of odour dispersion efficiency}

Figures 2 a) and b) illustrate the regression equations obtained from all the data collected, for the site without and with a windbreak, respectively. The least square analysis indicates that the windbreak did have a significant effect on odour level with distance from the source $(\mathrm{P}<0.5)$. Whereas the odour concentration was higher at the source, for the site with the windbreak, the odour concentration decreases faster downwind, compared to the site without the windbreak. This phenomenon results from the fact that the windbreak appears to hold the odours immediately on its leeward side and then release them with a dilution effect. Two regression lines were produced for each site. The higher line is computed from the zones of high odour intensity while the other line is computed from all the data collected on the individual sites. If a separation distance is computed from the maximum and overall lines, for both sites, $2 \mathrm{OU}$ is reached without the windbreak at a distance of 717 and $561 \mathrm{~m}$ from the source, 
while with the windbreak the distance is of 564 and $355 \mathrm{~m}$. Thus, the windbreak did reduce the separation distance by 21 and $37 \%$, respectively, for the maximum and overall data, as compared to the site without windbreak. In determining the separation distance, the maximum odour levels are preferred as they are more conservative than the overall data.
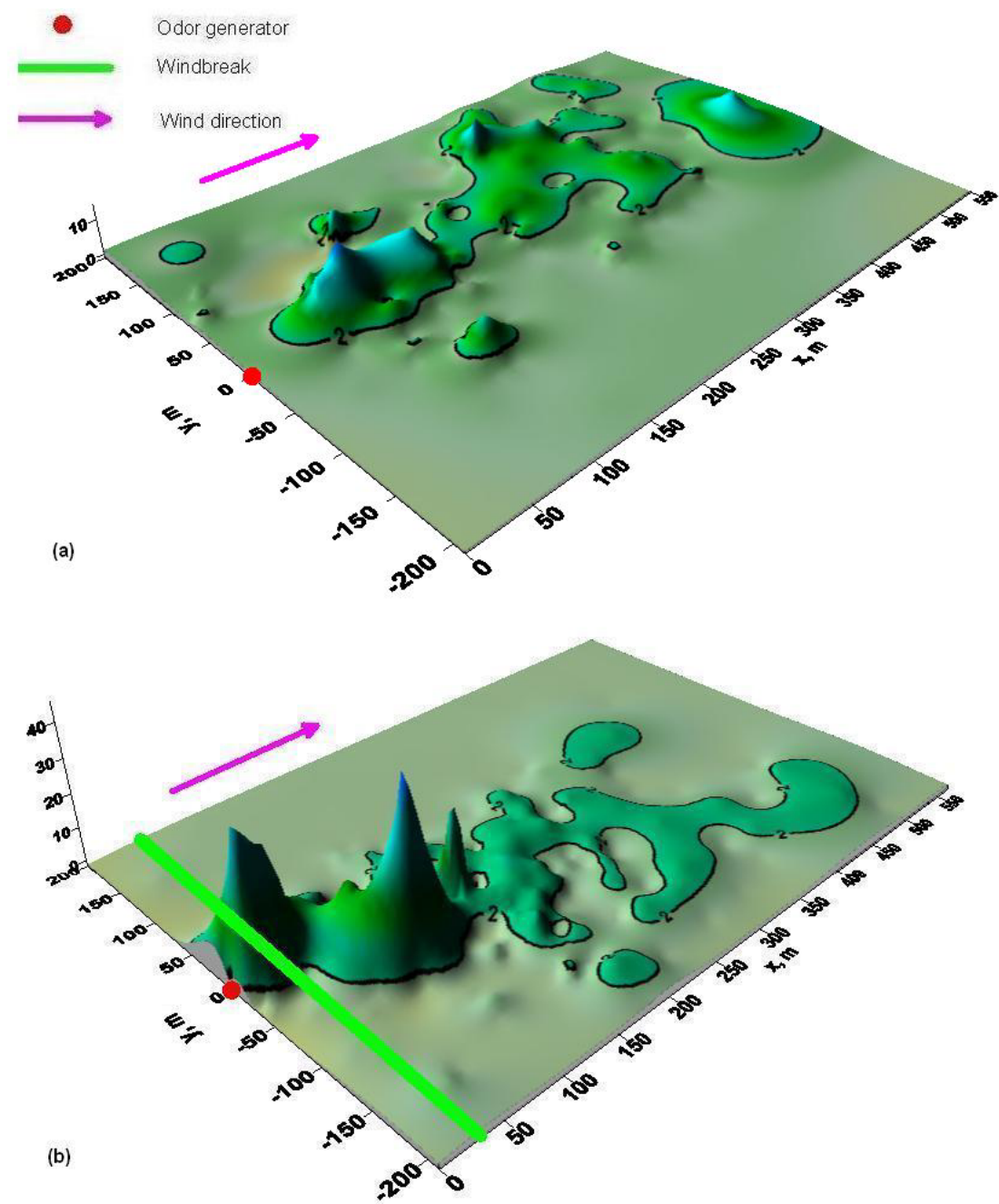

Figure 1: Typical odour plumes which developed in the absence (a) and presence (b) of a windbreak. An odour concentration of $2 \mathrm{Ou} / \mathrm{m}^{3}$ is used to draw the final contour of the odorous zones. 

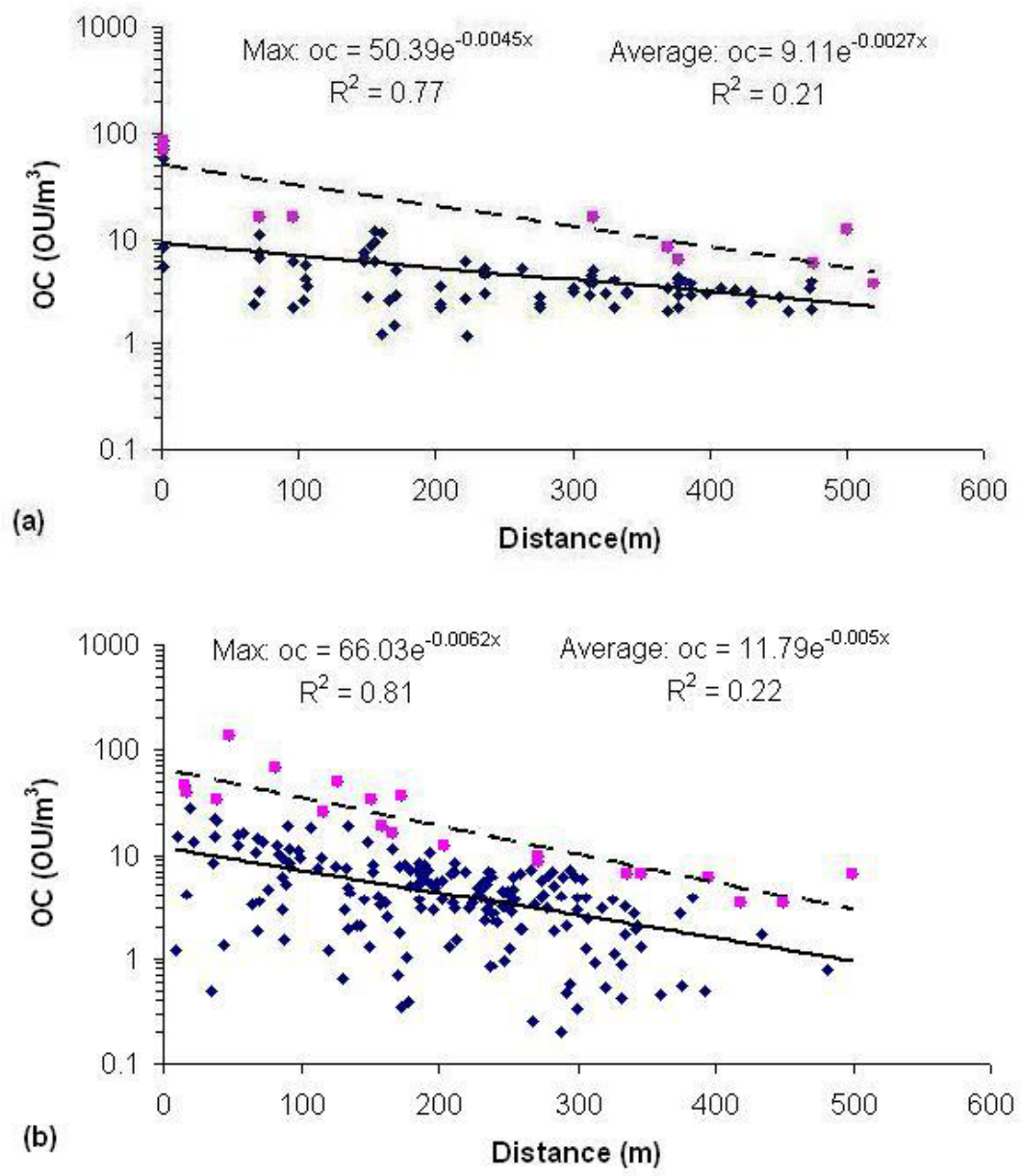

Figure 2: Odour concentration (OC) with distance from the source and regression lines for the site without (a) and with windbreak (b), for all the data collected and standardized. The top line is associated with the zones of peak odour concentration while the bottom line of each graph is associated with all the data.

\section{Conclusion}

This project observed the odour plumes which developed on a site without a windbreak and on another with a natural windbreak consisting of a single row of deciduous trees with an optical density of $35 \%$. The results indicate that natural windbreaks can effectively help dilute odours, by holding them immediately on their leeward site and then releasing them with a dilution effect. A regression 
analysis with classification indicated that the effect was significant at a $95 \%$ confidence level.

Therefore, windbreaks warrant further investigation to obtain the optimal value of parameters establishing their effectiveness in diluting odours. Parameters such as windbreak porosity and type of tree, wind direction and speed, ambient air temperature with height and therefore air stability or convective effects can affect the performance of windbreaks in diluting odours. Because field trials are expensive, time consuming and not perfectly controllable, it is advisable to work with a model simulating the dilution effect to windbreak.

\section{Acknowledgement}

The authors wish to acknowledge the financial contribution of Consumaj inc., CDAQ, The Livestock Initiative Program, Agriculture and Agro-Food Canada and the Natural Sciences and Engineering Research Council of Canada.

\section{References}

[1] Guo, H., Jacobson, L.D., Schmidt, D.R., Nicolai, R.E. \& Janni, K.A., Comparison of five models for setback distance determination from livestock sites. Canadian Biosystems Engineering, 46, pp. 6.17-6.25, 2004.

[2] Heisler, G.M. \& Dewalle, D.R., Effects of windbreak structure on wind flow. Agriculture, Ecosystems and Environment, 22-23, pp. 41-69, 1988.

[3] McNaughton, K.G., Effects of windbreaks on turbulent transport and microclimate. Agri. Ecosystem \& Environment 22-23, pp.17-39, 1988.

[4] SAS Institute. 1990. SAS/STAT, User's Guide. Volume 2, $4^{\text {th }}$ ed. Cary, NC, USA. SAS Institute Inc.

[5] Miller, I., Miller, M. \& Freund, J.E., John E. Freund's mathematical statistic, Prentice Hall: Upper Saddle River, New Jersey, USA, pp. 624, 1999. 